\title{
"EL PARO O ARGELIA": LA EXPATRIACIÓN DE LOS ESPAÑOLES EN ARGELIA COMO SALIDA LABORAL
}

\section{"ALGERIA VS UNEMPLOYMENT": THE EXPATRIATION OF SPANIARDS IN ALGERIA AS A JOB OPPORTUNITY}

María Jesús Cabezón Fernández ${ }^{*}$ y Juan David Sempere Souvannavong**

Resumen: La movilidad transnacional de personas cualificadas entre España y Argelia conoce un importante cambio a raíz de la intensificación de las relaciones comerciales bilaterales, dando lugar a una movilidad Norte-Sur. La instalación de empresas extranjeras en Argelia favoreció la movilidad de personas con alta cualificación motivadas por la posibilidad de desarrollar sus carreras con unas buenas condiciones laborales. La crisis económica y social ha provocado la intensificación de la movilidad transnacional española hacia Argelia, a la que se han unido pequeños empresarios y personas sin empleo que se lanzan a la búsqueda de un trabajo incluso de forma irregular. En este trabajo nos centraremos en analizar, con una aproximación cualitativa, cómo la crisis ha afectado a la movilidad transnacional de los expatriados españoles, que han pasado del privilegio a la precarización, en un contexto percibido como adverso, pero necesario para evitar el desempleo en España.

Palabras clave: movilidad cualificada; expatriados españoles; transnacional; precarización; Argelia.

* Universidad de Alicante.

** Universidad de Alicante. 
Abstract: High skilled transnational mobility between Spain and Algeria increased due to the intensification of the bilateral relationships, giving rise to a North-South mobility. The foreign enterprises set up in Algeria encouraged the high skilled mobilities as way to develop their professional careers in good labour conditions. Economic and social crisis provoked the intensification of the transnational mobility and emigration to Algeria, adding new actors like entrepreneurs and people unemployed who search for a job even in irregular condition. From a qualitative perspective, this paper focusses on analyse how the crisis reshaped the mobility of the Spanish expatriates, who changed privileges for precarisation, in a context perceived as adverse but necessary to avoid the unemployment in Spain.

Key words: High-skilled mobility; Spanish expatriates; transnationalism; precarisation; Algeria.

\section{INTRODUCCIÓN}

En 2013, la Organización Internacional para las Migraciones y la OCDE pusieron de manifiesto la aparición de una emergente tendencia migratoria Norte-Sur que venía a sumarse a las clásicas Sur-Norte, Norte-Norte y Sur-Sur. Países como España o Portugal representan casos paradigmáticos de una nueva emigración desde la Europa del sur hacia países europeos del norte, Estados Unidos o Reino Unido (Lafleur y Stanek 2017), así como hacia países emergentes del "Sur global" como Ecuador o Argelia.

En el caso español, la tendencia Norte-Sur se nutre de dos fenómenos derivados de los efectos que la crisis económica de 2008 ha producido en las estructuras de la sociedad española. Por un lado, la salida de las personas inmigrantes llegadas entre los años noventa y 2008 que, ante el agotamiento de sus estrategias en España, deciden retornar a sus países de origen o marchar a otro destino (Parella y Petroff 2013; López-Sala y Oso 2015). Por otro lado, la salida de personas españolas autóctonas, fenómeno muy debatido en sus inicios debido a la dificultad de su cuantificación dadas las herramientas estadísticas disponibles (Domingo y Sabater 2012). Si las investigaciones iniciales se centraron en la emigración 
joven y cualificada (Santos Ortega, 2013), trabajos posteriores señalaron que la emigración española engloba diferentes perfiles según edad y cualificación (Rodríguez Fariñas, Romero Valiente e Hidalgo Capitán, 2017; 2015), coincidiendo con la tendencia observada en nuestra investigación (Sempere Souvannavong y Cabezón Fernández, 2016).

La incipiente movilidad de españoles-as expatriados-as hacia Argelia comenzó a incrementarse a partir de 2005 tras la firma del Acuerdo Euromediterráneo, que sentó las bases para la ampliación de las relaciones bilaterales (Cabezón Fernández, 2017). Las empresas españolas encontraron en Argelia un lugar en el que internacionalizarse promoviendo la expatriación de personal. En este periodo, la movilidad laboral hacia Argelia era percibida por las personas trabajadoras, como una fórmula para conseguir una experiencia internacional que les permitiera promocionar en el futuro. Sin embargo, la crisis económica de 2008, que ha tenido como una de sus consecuencias la reducción del mercado laboral, ha provocado una segunda etapa de expatriaciones marcada por la precariedad. Las empresas transnacionales, además de mermar las condiciones de expatriación, están reduciendo el número de asignaciones internacionales debido a los costes que esta práctica supone a la empresa.

En este artículo analizamos bajo el paraguas de la teoría transnacional y el paradigma de la movilidad, cómo la crisis económica y social ha transformado las formas de movilidad cualificada hacia Argelia, y propiciado la aparición de nuevas estrategias transnacionales. Así mismo, con este trabajo empírico pretendemos aportar datos para la reformulación de la visión dominante de la persona "expatriada" cómo "trabajadora móvil", independiente y cosmopolita, que decide iniciar una experiencia transnacional para mejorar su perfil profesional. Tal y como señalan Bochove y Engbersen (2015) coincidiendo con nuestra propuesta, la expatriación puede responder a una acción impuesta, no aceptada pero llevada a cabo por el miedo a las represalias de la empresa, o bien por el miedo al desempleo. En segundo lugar, la expatriación en Argelia lejos de mostrar el intercambio cultural entre expatriados y población autóctona supuesta por el cosmopolitismo, apunta hacia un cosmopolitismo desarrollado entre expatriados-as en "lugares internacionales" como hoteles o restaurantes, sintiéndose en casa sólo en su burbuja de expatriados (ibid 2015: 295). 


\section{MOVILIDAD VS EMIGRACIÓN TRANSNACIONAL EN LAS SOCIEDADES GLOBALES}

Desde que se iniciara la globalización, la lógica de la movilidad de población se ha visto aumentada por la expansión de la idea de modernidad (Cortes y Faret, 2009: 7) apoyada en la proliferación de líneas de transporte, el abaratamiento de sus costes o la facilidad de movimientos en espacios comunes (como el espacio Schengen). Los cambios que la globalización ha producido en las sociedades actuales han dado lugar a que los proyectos vitales puedan realizarse acumulando recursos en el país de origen y en otros territorios a los que se accede mediante la movilidad espacial.

En este contexto, la teoría transnacional de las migraciones aborda el estudio de las formas alternativas de movilidad de población que no responden a la clásica visión lineal de migraciónasentamiento. Dicha aproximación propone que los procesos migratorios se desarrollan entre dos o más países, manteniendo las redes sociales afectivas y/o laborales de forma simultánea, sin romper con el país de origen, creando así espacios supranacionales denominados "espacios sociales transnacionales" (Schiller, Basch y Blanc-Szanton, 1992). En torno a este argumento se ha elaborado una teoría social que analiza los fenómenos migratorios en las sociedades transformadas por los procesos de la globalización (Peggy Levitt y Glick Schiller, 2004). La teoría transnacional ha dedicado parte de sus esfuerzos al análisis de nuevas formas de asentamiento de las diásporas transnacionales (Dahinden, 2010), que sin embargo no encajan con los actores sociales de nuestro fenómeno observado. Además, tampoco llega a cubrir la multiplicidad de flujos observados, por ello, la teoría transnacional juega un papel de telón de fondo en el que enmarcar las propuestas del paradigma de las "Nuevas Movilidades" (Sheller y Urry, 2006; Faist, 2013). Esta aproximación teórica propone el estudio del movimiento de flujos de personas, productos, ideas, imágenes e información de un lugar a otro, enmarcados en redes en constante tensión entre la inmovilidad y la movilidad, entre la territorialidad y la desterritorialización (Jensen, 2011: 256). La movilidad geográfica, en este contexto, se entiende como un recurso en sí mismo, a través del cual acceder al capital necesario para desarrollar los proyectos de vida. Gracias a ella, se puede tener acceso a recursos más allá de las fronteras nacionales, representando, la movilidad, "el principal marcador de diferencia 
y de estratificación social de nuestro tiempo" (Oso, Sáiz López y Cortés, 2017: 5).

Una propuesta reciente que combina ambas teorías es el modelo de las "movilidades cruzadas" (Oso et al.), que persigue analizar las dinámicas transnacionales desarrolladas por individuos y familias para lidiar con los contextos de incertidumbre propiciados por la conjunción del proceso de globalización y la crisis financiera. Esta propuesta sitúa en el centro del estudio a individuos y familias para analizar las movilidades cruzadas atendiendo a los elementos móviles e inmóviles que conforman la movilidad incorporando la perspectiva de género e intergeneracional de forma transversal. Si bien, en nuestro estudio no aparecen segundas generaciones, los roles de género, así como la dualidad móvil e inmóvil representan aproximaciones presentes en nuestro estudio.

\section{LOS EXPATRIADOS: MIGRANTES CON RECURSOS Y ACTORES DE LA MOVILIDAD LABORAL}

Diferentes escuelas de pensamiento han analizado las estrategias migratorias desarrolladas por los migrantes con recursos. Vailati y Rial (2016) analizan la evolución de los términos acuñados a este grupo de migrantes como "expatriados", "profesionales migrantes", "migrantes ricos", así como los fenómenos asociados a ellos como la "fuga de cerebros". Sin embargo, el estudio de los migrantes cualificados ha sido un tema relegado en favor de la inmigración sin recursos en dirección Sur-Norte y Sur-Sur.

El concepto "expatriado" en términos laborales, define a aquella persona que trabaja en una empresa transnacional y que es transferida por la empresa matriz a una filial en otro país, con el objetivo de dirigir la implantación de una nueva sede, formar equipos locales, etc. Este concepto, que proviene del área de la economía y recursos humanos, se popularizó en los años dos mil por el uso que hicieron de él los medios de comunicación (como pasara con la categoría "movilidad"), provocando el rechazo del concepto por parte de la comunidad científica dedicada al estudio de las migraciones. Por ello, resulta necesario reflexionar sobre quiénes son las personas "expatriadas".

La expatriación o asignación internacional de personas es una estrategia empresarial habitual realizada por las compañías trans- 
nacionales. Esta práctica responde a la lógica de la transformación de los mercados internacionales en mercados transnacionales como parte del proceso de globalización. Las principales capitales mundiales, en las que se definen y desarrollan las prácticas económicas y sociales capitalistas, se convierten en "ciudades globales" (Sassen, 2003), en las que las relaciones comerciales e institucionales sobrepasan las fronteras operando en un marco supranacional. En estos centros económicos, las personas que desempeñan cargos directivos y de responsabilidad, dirigen y controlan los principales sectores económicos mundiales. La "élite directiva" (Beaverstock, 2005) o "clase capitalista transnacional" (Sklair, 1997), está compuesta por "trabajadores móviles" que deciden, por motivación personal, desarrollar una actividad laboral en el extranjero que les permita ascender en su trayectoria profesional. Estas experiencias son valoradas en tanto en cuanto son una forma de adquirir un carácter cosmopolita al adaptarse a diferentes entornos culturales sin esfuerzo gracias al capital económico, social y simbólico (Bourdieu, 1989) reunido en su trayectoria profesional.

Sin embargo, algunos investigadores han criticado estas categorías por tender a la homogenización del grupo (Beaverstock, 2005; Sklair, 1997), así como por la escasa atención prestada al análisis de las prácticas diarias en el espacio local (Yeoh y Willis, 2002, 2005; Meier, 2015). Desde la aproximación postcolonial, la categoría de Westerner parte de la jerarquización del mundo en centro y periferia, para englobar a los "expatriados blancos" de los países del centro, a los profesionales independientes y a los "aventureros masculinos y blancos” (Meier, 2015: 5). Fechter y Walsh (2010), en línea con esta propuesta, analizan cómo los expatriados construyen y reconstruyen su identidad de grupo en relación "el otro". El proceso parte de una "sensación de superioridad" determinada por la estratificación del mundo en países de diferente nivel provocando comportamientos neocoloniales. Sin embargo, son numerosas las investigaciones que optan por el término "expatriado" por ser con el que los actores sociales se identifican, más allá de otras construcciones teóricas. Un ejemplo de ello es el trabajo de Leonard (2010) en el que aborda el día a día de los expatriados británicos en Hong Kong, o la investigación de Bochove y Engbersen (2015), que no se centra en una nacionalidad específica, sino en la experiencia multinacional desarrollada en Ámsterdam. Siguiendo estos trabajos, así como las investigaciones de Yeoh y Willis $(2002 ; 2005)$, dado que nuestros 
actores se identifican con el término "expatriado", adoptamos esta categoría en la que incluimos a las personas que trabajan en una empresa española y se trasladan a Argelia trabajando en la misma empresa; a las personas que trabajan para una institución pública en España y se marchan a Argelia; así como a las parejas de éstas.

\section{METODOLOGÍA}

El objetivo de esta investigación es profundizar en las estrategias transnacionales desarrolladas entre España y Argelia por las personas españolas expatriadas por motivos laborales. Para ello, prestaremos especial atención a las transformaciones que la crisis económica y social han provocado tanto en los itinerarios como en las practicas diarias en Argelia. Siguiendo la apuesta metodológica de trabajos con un objeto de estudio similar (Leonard, 2010; Coles y Walsh, 2010, entre otros), y dado que nuestro objetivo es mostrar la realidad de un colectivo de emigrantes españoles invisible dentro del fenómeno general de la emigración española actual, se ha optado por una metodología cualitativa.

La recogida de datos empíricos se ha realizado entre 2012 y 2016 mediante trabajo de campo multi-situado en ambos países. La entrevista en profundidad con apoyo de cuestionario semiabierto ha sido la principal técnica de recogida. El cuestionario estaba dividido en tres bloques que abordaban el contexto inicial del entrevistado, motivaciones, proceso de toma de decisión sobre el destino y los itinerarios de movilidad; el desarrollo de la vida diaria en Argelia en relación con la población local y la sociedad de origen; y las expectativas de futuro y su percepción sobre la evolución del fenómeno debido a la crisis. Parte de las entrevistas se realizaron en espacios del ámbito profesional y en espacios de la vida cotidiana, como viviendas familiares y lugares de ocio como hoteles y restaurantes, lo que nos permitió observar sus ámbitos de producción social habitual.

Se realizaron 38 entrevistas (alcanzando el punto de saturación), a las que se añaden 10 a informantes clave. El perfil es el de hombres y mujeres que actualmente desempeñan una actividad laboral en Argelia, en una empresa privada o institución pública, o que en la actualidad han retornado o cambiado de país. Se incluyen las parejas 
acompañantes, todas ellas mujeres, entrevistas sin la presencia de la pareja. Nuestro actor social tiene entre treinta y cincuenta años, y de los que el cincuenta por ciento, aproximadamente, tiene conocimientos de francés.

Mediante la técnica de bola de nieve se accedió a los entrevistadosas a través de los informantes clave, en su mayoría personal recursos humanos que facilitaron el contacto de personas expatriadas en la actualidad. Éstas nos condujeron a trabajadores de otras empresas y sectores productivos con los que compartían vivienda o actividades de ocio. Por otro lado, para evitar sesgos, se contactó con potenciales entrevistados-as mediante Linkedln y Facebook, accediendo a perfiles de diferente procedencia y lugar de destino.

\section{ARGELIA: DESTINO DE LA EXPATRIACIÓN ESPAÑOLA}

España y Argelia se encuentran sólo a $300 \mathrm{Km}$. de distancia, siendo una de las razones que explican los intensos intercambios comerciales y migratorios que ambas regiones han mantenido desde hace siglos. A lo largo de la Edad Moderna, la expulsión de los moriscos (1609) o los intentos de ocupación del litoral argelino, y en especial de Orán (siglos XVI-XVIII), por parte de España son dos de los capítulos más significativos de estas relaciones. Durante el periodo colonial (1830-1962) la fortísima emigración española a la Argelia francesa hizo que la mayoría de los europeos presentes, sobre todo de la parte occidental, fueran españoles, franceses de origen español o descendientes de estos. Este pasado compartido junto con la proximidad geográfica explica que muchos españoles, cuando visitan Argelia, sientan cierta proximidad debida a la similitud del clima, a la arquitectura de los barrios más antiguos e incluso a ciertas costumbres.

Con la independencia de Argelia (1962), las relaciones bilaterales entre la España franquista y Argelia fueron escasas, hasta 1974, cuando tras la crisis del petróleo de 1973, se empezaron a construir relaciones entorno al sector energético. En 1975, la retirada de España del Sahara Occidental y el surgimiento del conflicto entre Marruecos y Argelia por la cuestión saharaui, hace emerger un segundo gran tema de negociación entre España y Argelia. A ellos se suma la cuestión securitaria, primero sobre la guerra civil argelina 
(1988-1999), y posteriormente sobre el terrorismo islámico que surge a partir de los años dos mil ${ }^{1}$.

Desde los años ochenta, Argelia sufre un problema de desempleo estructural de los jóvenes provocado, en parte, por la concentración de su economía en el sector energético (Zoubir y Amirah, 2008). Gracias a los hidrocarburos ${ }^{2}$, Argelia multiplica la entrada de divisas desde 1999 permitiéndole paliar parte de esas deficiencias. Esta riqueza de recursos naturales y la cercanía, junto a la necesidad de España de desvincular su dependencia energética de Libia, dieron lugar a que en 1974 llegara a Argelia la primera gran empresa española, Enagas, tras la firma de un acuerdo con la empresa pública argelina Sonatrach. Otras empresas españolas llegarán a Argelia a partir de 2005 con la firma del Acuerdo Euromediterráneo de Vecindad. Éste ponía el marco para una mayor y diversa colaboración comercial, tendencia que se anima a partir de los años 2008, cuando la internacionalización empresarial española comienza a diversificar sus destinos tradicionales en la UE y América del Sur, hacia Oriente Próximo y Norte de África (Torres Villanueva, 2009). Este flujo empresarial coincide con la aprobación, en 2010, de los Planes Quinquenales elaborados por el gobierno argelino con el objetivo de diversificar su economía y mejorar sus infraestructuras mediante megaproyectos de licitación pública (Cabezón Fernández y Sempere Souvannavong, 2015). Estos proyectos representan un nuevo "El dorado" (Bredeloup, 2016) que está propiciando la llegada de empresas extranjeras a Argelia, así como de otros perfiles de "expatriados, instalados y pioneros", sobre todo a partir de 2009 (Fabbiano, 2016: 17).

Si observamos el número de permisos de trabajo concedidos por Argelia a nacionales extranjeros, el incremento de las cifras se hace patente ya que, de 1.107 permisos concedidos en 1998, pasa a 50.760 en $2012^{3}$. La medición estadística del flujo de españoles hacia Argelia sufre los mismos problemas metodológicos que el fenómeno general. En nuestro caso particular, esta dificultad deriva

1 Sobre las relaciones bilaterales hispano-argelinas, algunas obras destacadas son: Thieux Jordá (2012), Larramendi y Mañé Estrada (2012), Marquina Barrio (2012), Bustos (2007), López García y Larramendi (2005). dólares.

2 Entre 1998 y mediados de 2014, el precio del petróleo pasó de 10 a 110

3 Datos disponibles en http://cadmus.eui.eu/bitstream/handle/1814/27394/ MPC_NeighMigration.pdf? sequence $=5$ 
de que los expatriados tienen su residencia fijada en España para evitar la doble imposición fiscal y poder repatriar el mayor capital posible. Un indicador útil para hacernos una idea aproximada de la movilidad entre ambos países es el tránsito de pasajeros aéreos entre ambos países. Este recoge que entre 2006 y 2016, se ha quintuplicado el número de pasajeros pasando de 118.952 a 599.4464 . Sin embargo, el problema de medición queda patente si acudimos a la Estadística de Variaciones Residenciales que en 2013 reflejaba que 74 personas españolas habían marchado a Argelia. Un dato que contrasta con la afirmación del cónsul general de España en Orán que, en el mismo año, señalaba: sólo en la ciudad de Orán había cerca de 1.300 personas españolas en la ciudad la mayoría de ellas sin estar registradas "de matrícula" (Cabezón Fernández y Sempere Souvannavong, 2015).

\section{CRISIS Y TRANSFORMACIONES EN LAS FORMAS DE MOVILIDAD LABORAL}

Alfredo es un español que desde 2009 ha realizado dos expatriaciones en Orán: la primera entre 2009 y 2010 y la segunda entre 2012 y 2016. En ambos casos ha desempeñado el mismo puesto que realiza en España para su empresa. Respecto a su familia, en la primera expatriación Alfredo marcha en solitario mientras Elena permanece inmóvil en España, ya que en esos momentos ella tiene un empleo y la movilidad laboral de Alfredo se plantea como algo temporal. Sin embargo, en 2012, Elena se encuentra desempleada, por lo que decide marcharse con Alfredo en la segunda expatriación a Orán. Alfredo describe (en 2013) cómo han cambiado las motivaciones y condiciones de trabajo en una empresa transnacional española:

“[En 2009] Las condiciones de expatriación estaban pactadas previamente con la empresa que contaba con un plan de expatriación: viajes por mes, apartamento, coche con chófer, mujer de la limpieza, seguro de vida y médico. La empresa se encarga de los

4 Datos disponibles en http://www.aena-aeropuertos.es/csee/Satellite/ aeropuertos/es/Page/1046686258517//Estadisticas.html 
pagos y se cotiza en los dos países. [ ] Antes la expatriación significaba una mejora en la carrera profesional, ahora no. Además, las expatriaciones se están reduciendo por las reducciones de plantilla. Además, antes cuando se repatriaban tenían un puesto en la empresa, ahora en muchas ocasiones ya no".

La experiencia de la familia de Raquel y Enrique en Argel se desarrolla entre 2011 y 2015. Enrique trabaja en Sevilla en un puesto de responsabilidad mientras que Raquel, debido a los ingresos de un negocio familiar, se dedica a las actividades reproductivas y de cuidados de la familia. En una expatriación previa, Enrique, Raquel y sus dos hijos se marchan juntos a Francia expatriados por su empresa sevillana. Será en 2011, al término del contrato cuando la empresa les plantea una nueva expatriación en Argel. Raquel, nos explica los elementos que influyeron en la toma de decisión:

“Argelia fue una propuesta a la que no se podía decir que no. [ ] Cuando termina [Enrique] en Francia no hay nada en España y la opción real era ir a Argelia manteniendo la calidad económica, no de vida [ ] no había alternativa en la empresa de mi marido ni tampoco en Sevilla, que no hay mucha oferta en la ingeniería. Se lo dicen a final de 2010 y España ya estaba en plena crisis. Un puestazo en Argelia casi teníamos que estar agradecidos”.

Años más tarde, en 2014, Pau marcha de Madrid para iniciar una expatriación en Argelia propuesta por la empresa de transporte marítimo en la que trabaja. Tras una expatriación previa durante cuatro años en Estados Unidos, inicia su primera experiencia en un país emergente. En este caso, su pareja permanece inmóvil en Barcelona mientras Pau vive entre semana en Argel, y en Barcelona el fin de semana. Él nos explica como tomó la decisión de marchar:

"Si [la empresa] te hace la oferta y dices no, te ponen la cruz y si dices sí, te lo tomas como una experiencia. Después de cuatro años en Estados Unidos esto [Argelia] es lo opuesto, me motivó en ese sentido y además que está cerca de Barcelona y puedo ir todos los fines de semana y lo hace más llevadero [ ] Las condiciones eran sueldo de España exento de impuesto de renta, dos viajes por mes, sueldo asignado en Argelia, vivienda, seguro médico internacional además del puesto de trabajo garantizado a la vuelta [] Ser un expatriado de semana laboral lo hace todo mucho más llevadero". 
Los discursos de estas personas reflejan los argumentos compartidos sobre cómo la crisis ha influido en sus motivaciones y contextos respecto al proceso de toma de decisión de iniciar una movilidad transnacional en Argelia. Si bien, la multiplicidad de formas familiares y contextos hacen de estas experiencias ejemplos que no pretenden su generalización, sino mostrar algunas de las estrategias realizadas por estas personas en el marco de la movilidad laboral en contextos de crisis.

Como podemos observar a través de las citas escogidas, la principal transformación introducida por la recesión es la motivación para la marcha, esto es, evitar el desempleo a toda costa incluso cuando las condiciones de expatriación ya no son percibidas como favorables. Si hasta 2012 la movilidad laboral hacia Argelia representaba una oportunidad deseada y decidida de forma individual (Beaverstock, 2005; Yeoh y Willis, 2005; Sklair, 1997), posteriormente, los efectos de la crisis provocan que la expatriación se sienta como a una acción impuesta por la empresa o por la situación del mercado laboral, siendo una práctica no deseada pero necesaria. La segunda transformación más acusada introducida por la crisis se refiere a los cambios en las estrategias y formas de movilidad realizadas por estas personas, precisamente ligadas a la necesidad de evitar el desempleo. En este sentido, las personas expatriadas y las familias transnacionales deciden prolongar o iniciar itinerarios alternativos en Argelia (Figura 1) como forma de alargar la actividad laboral de uno o varios miembros de la unidad familiar.

La experiencia de Alfredo y Elena (Experiencia de movilidad 1, Figura 1) representa al grupo de personas que realizaban una movilidad laboral en Argelia en tiempos de bonanza, motivados por obtener una experiencia internacional recompensada con buenas condiciones de expatriación. Argelia representaba un destino desconocido pero positivo para el futuro profesional, al que los españoles comenzaban a marchar. Alfredo en su discurso apunta a esos grandes proyectos reflejados en el Plan Quinquenal (2010-2014) lanzado por el gobierno argelino mencionados anteriormente. En la ciudad de Orán, varios de esos proyectos contaron con participación española como la construcción del Palacio de Congresos y Exposiciones (OHL) o el Hotel Le Meridien (OHL), la red de tranvía (Isolux) y el saneamiento y gestión del sistema de aguas (Aguas de Barcelona) en la ciudad de Orán.

Si bien su primera expatriación se planteaba como una movilidad de corta duración y de retorno seguro, en el que marcha 
en solitario mientras Elena continúa inmóvil en España, con el avance de la crisis, se producen procesos de sedentarización (Faist, 2013), gravitando entre la movilidad y la migración circular transnacional. Alfredo, al finalizar la primera experiencia vuelve a Alicante dónde pasa 9 meses hasta que la empresa le propone una segunda expatriación. En este caso, ya en 2012, Alfredo y Elena marchan juntos ya que Elena no tiene un empleo en España. Ambos permanecen en Oran hasta el fin de contrato, cuando deciden cambiar de estrategia y no retornar a España. Continúan en Orán gracias a que Alfredo se establece como consultor independiente para la misma empresa, que ha sido absorbida por una empresa multinacional francesa. De esta forma, consiguen mantener la actividad laboral en Orán en vez de retornar a su ciudad de origen con escasas posibilidades laborales.

\section{FIGURA 1}

\section{ITINERARIOS DE LAS MOVILIDADES REALIZADAS ENTRE ESPAÑA Y ARGELIA (2009-2016)}
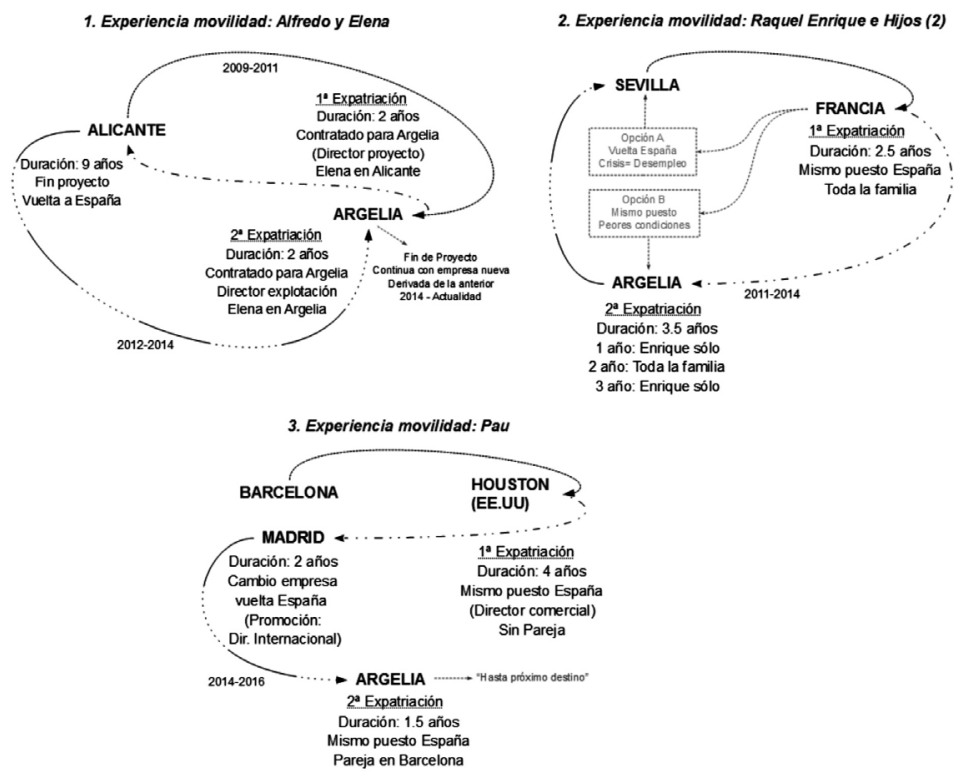

Fuente: elaboración propia a partir del trabajo de campo. 
La segunda fase de las expatriaciones hacia el norte de Argelia está marcada por los cambios producidos por la crisis. Si en el caso de Alfredo y Elena estos han producido un proceso de sedentarización en su estrategia de movilidad, en el caso de Enrique y Raquel provoca el inicio de una movilidad transnacional de su familia en Argelia (Experiencia de movilidad 2, Figura 1). Incluso cuando las condiciones de expatriación han empeorado al percibir un sueldo similar al que recibirían en España, la reducción de bonus y viajes, así como la imposibilidad de pactar la repatriación, Argelia se convierte en una estrategia necesaria para evitar el desempleo. La empresa no puede ofrecer un puesto de trabajo a Enrique en Sevilla, por lo que aceptan Argelia como destino. La expatriación se realiza en el mismo puesto, pero no con las mismas condiciones, por lo que no se percibe que se mantenga la misma calidad de vida que en Francia, aunque se entiende que es más positiva que la que tendrían en España si hubieran retornado. El imaginario previo que la pareja se ha formado sobre Argelia, marcado por las diferencias culturales y la cuestión securitaria junto a las condiciones de expatriación, determinan un itinerario de movilidad diferente al anterior. Primero marcha Enrique a Argelia durante un año mientras la familia permanece en Sevilla, y posteriormente, Raquel y sus hijos pasan de la inmovilidad a la movilidad, trasladándose a Argel. Raquel en su discurso muestra como el miedo a una posible ruptura debido a la distancia influye en su decisión de unirse a Enrique junto con sus hijos, como elementos móviles de la familia. Tras un año de convivencia conjunta Raquel y sus hijos retornan a Sevilla debido a problemas de salud, permaneciendo Enrique en movilidad. Finalmente, un año después Enrique vuelve a Sevilla como desempleado para establecerse posteriormente como autónomo.

En estas prácticas, la cercanía geográfica favorece que las estrategias de movilidad se reproduzcan durante largos periodos de tiempo hacia la circularidad, que se mantiene "mientras la cabeza aguanta" (Pau, entrevistado 2016). La proximidad permite las visitas regulares a la familia, un factor determinante que diferencia Argelia frente a otras regiones como América Latina en las que no podrían mantener el mismo grado de movilidad. Tal y como señalan Bochove y Engbersen (2015), parte de las personas expatriadas en Ámsterdam elegían el destino por la cercanía geográfica al permitirles mantener sus redes sociales en el lugar de origen. Pau (Experiencia de movilidad 3, Figura 1) representa el ejemplo más 
intenso de persona móvil. En su discurso se define como "expatriado de semana laboral" trabajando en Argelia de domingo a jueves ${ }^{5}$ y pasando los fines de semana en España, incluso cuando la empresa no corre con los gastos del viaje. Sin embargo, Pau cuenta con esta situación gracias a su rango en la empresa, ya que personas en otros puestos y sectores productivos como la construcción (en el que sólo se descansa un día a la semana), las estancias en Argelia se alargan hasta periodos de mes y medio sin visitar a la familia. Un hecho que permite a Pau vivir de forma desconectada de la sociedad argelina, como veremos a continuación.

Estas experiencias junto a las de otros entrevistados, revelan una ruptura con la visión tradicional de las personas expatriadas, la movilidad de corta duración intercambiable entre ciudades globales y la visión cosmopolita del expatriado como personas con interés por las diferentes culturas del mundo. En nuestro estudio, la mayoría de las personas entrevistadas continúan en Argelia o han vuelto a España, lo que produce que estas personas sean móviles entre dos países en ciudades que no se corresponden con las "ciudades globales". Estas personas viajan al norte de Argelia no porque lo encuentren interesante, sino porque sus empleadores así lo quieren, siendo positivo para sus carreras: son personas corporativistas ambiciosas más que curiosos trotamundos (Bochove y Engbersen, 2015: 297), e incluso en los últimos años es el desempleo y no la ambición, la motivación para la movilidad, por lo que no la ambición sino la necesidad, les convierten en trabajadores transnacionales precarizados.

\section{DEL COSMOPOLITANISMO A LA BURBUJA DE LA EXPATRIACIÓN}

En la literatura de la década de los dos mil, el expatriado se representaba como una persona que se mueve de forma voluntaria "que decide vivir en el extranjero durante un tiempo y que sabe que puede volver a casa cuando lo requieran" (Hannerz, 1990: 243). La movilidad representa una estrategia para adquirir aptitudes cosmopolitas aplaudidas por el discurso de la modernidad, y que

5 Viernes y sábado son el fin de semana oficial en Argelia 
responde a su ethos cosmopolita, entendido como la apertura hacia otras culturas y el deseo de incorporar aspectos de esta en la construcción de su propia identidad (Vertovec y Cohen, 2002). Sin embargo, en nuestro estudio observamos que la movilidad laboral hacia un país periférico producida en un contexto de crisis global no propicia actitudes cosmopolitas hacia otras culturas, sino la producción y reproducción de continuidades postcoloniales. Estas personas producen prácticas sociales en espacios alejadas de la sociedad argelina, enmarcados en los "enclaves de expatriados" o burbujas en las que se profesa el cosmopolitismo resultante de la sociedad inmersa en los riesgos globales (Beck, 2008; Beck y Grande, 2006) entre otros expatriados internacionales.

Pau, relata cómo percibe la vida diaria propia y de los expatriados dentro de la "jaula de oro" de los expatriados:

"Las familias extranjeras que he visto se limitan a cenas en casa con amigos de la colonia francoparlante y actividades del Instituto Francés, no es una vida integrada en el país sino con la colonia que hay".

Juana, con dos hijos trabajadora en Argel entre 2006 y 2015, describe el día a día a su llegada, que transcurría dentro de la "burbuja" (entendida como espacio imaginado) de forma similar a los patrones desarrollados por la "colonia española" en Argel:

"Los primeros meses fueron muy duros, es un país que o lo quieres o lo odias, no hay un término medio. Muy duro [ ] pero llegó un día en el que dices jesto no va a poder conmigo! y te planteas otra cosa. De vivir en una burbuja como muchísimos españoles hacen, pues decir: ¡se acabó! tengo que salir a la calle, tengo que integrarme, tengo que aprender el idioma y tengo que convivir con los argelinos, y eso hice".

La mayoría de las personas entrevistadas coincide en la descripción de la burbuja como forma de vida al inicio de su experiencia. En los primeros meses las actividades fuera del ámbito laboral se reducen a desplazarse entre la residencia y el puesto de trabajo. Las compañías ofrecen coches de empresa con o sin conductor, a la persona trabajadora y a su pareja. A medida que la experiencia avanza, la mayoría de los entrevistados decide abandonar el servicio del conductor para trasladarse ellos mismos con el vehículo o a pie. El 
"chófer" suele ser una de las primeras personas de la sociedad local con las que el expatriado tiene contacto, a través de la cuál acceden a información básica sobre el desarrollo del día a día, así como de las costumbres y su cultura, si se llega a entablar mayor grado de confianza. Las personas británicas y singapurenses desplazadas en China (Yeoh y Willis, 2005) o Hong Kong (Leonard, 2010) coinciden con estas prácticas. "Salir a la calle" significa un primer reto para estas personas de cara a "quitarse el escudo". El ir en solitario por las calles se percibe como un reto debido a la incertidumbre que genera la diferencia cultural y la falta de conocimientos (en su mayoría) de los idiomas oficiales o mayoritarios, favoreciendo el aislamiento y el escaso contacto con la población argelina.

Las personas expatriadas se relacionan con la población autóctona en la esfera laboral sin llegar a establecer relaciones personales, en la que se relacionan de forma instrumental (Korpela 2010). En el caso de las familias con hijos, la pareja acompañante es la que, a través de las actividades escolares o de ocio en relación con los niños, propicia la apertura del grupo social respecto a algunas personas argelinas y, sobre todo, personas de otras nacionalidades, como sucede en el caso de las mujeres españolas acompañantes en México estudiadas por Mendoza y Guitart (2006).

Al inicio de la expatriación en Argelia, algunas personas residen en hoteles hasta pasados unos meses, cuando se trasladan a viviendas unifamiliares en busca de un lugar más personalizado y con mayores comodidades. Otras, dependiendo de la política de empresa, se trasladan desde el inicio a una vivienda unifamiliar en un edificio independiente, o bien en un edificio alquilado por la empresa para todos los trabajadores y familiares. Con esta práctica, "la burbuja" es más infranqueable ya que favorece que las personas entrevistadas se sientan en "familia" por lo que no necesitan "a nadie más para sentirnos acompañados". "Sabemos que hay una colonia de españoles, pero todos juntos no tenemos la necesidad de buscar a otras personas" (Juan, primera experiencia en Argelia, 2014).

El ocio se convierte en un elemento determinante de la estancia en Argelia. Para la población española, con representaciones del ocio que responden al modelo occidental y globalizado, el ocio se percibe como escaso en sus ciudades de residencia. La falta de centros comerciales, espacios verdes abiertos, tiendas de moda y centros culturales internacionales aumenta la sensación de aislamiento. Este hecho influye en la decisión de permanecer en sus casas 
dedicando el tiempo libre a comunicarse con sus redes de familiares y amigos situados en otros lugares (Willis y Yeoh, 2002), en vez de realizar actividades que faciliten el contacto con la población local. Los encuentros con otros españoles se realizan en casas y "enclaves de expatriados"(Beaverstock, 2005), como restaurantes y hoteles internacionales que cuentan con cafeterías y gimnasios “occidentales". El Instituto Francés en Argel y los Institutos Cervantes son los centros culturales de referencia representando, además, el papel de agente socializador para las parejas de expatriados, ya que la mayoría de ellas encuentra un empleo a tiempo parcial que les permite realizar actividades fuera del aislamiento del lugar de residencia. En verano, las playas privadas se convierten en un espacio de ocio similar al que realizan en España. Los entrevistados Alfredo y Elena afirman que: "en las playas privadas pagas y tienes de todo, es como si estuvieras en otro país, motos, música... hacemos bromas sobre si es Ibiza. Van extranjeros y emigrantes retornados. Este periodo estival en la playa se convierte en un pulmón”.

En el discurso sobre las prácticas diarias y el trato con la sociedad argelina, observamos como los españoles se posicionan en una situación superior al "otro" argelino, cuando muestran sus opiniones sobre sus comportamientos y costumbres, ya sea en el ámbito laboral o personal. Investigaciones realizadas desde la aproximación de las desigualdades sociales (Weiss, 2005) o la teoría postcolonial (Leonard, 2010), analizan cómo las movilidades laborales reproducen las desigualdades sociales más allá de las fronteras nacionales. La división del mundo en países del centro y periferia, producen comportamientos de superioridad de las sociedades centrales respecto a las sociedades periféricas, atribuyéndoles capacidades inferiores (Korpela, 2010). Los comportamientos y actitudes coloniales pueden desarrollarse hacia sociedades que históricamente han sido colonias y también hacia sociedades que no han sido colonizadas, pero que forman parte de la periferia mundial (Weiss, 2005). Por "comportamiento colonial" se entiende la infravaloración de la sociedad de destino, aduciendo que sus costumbres y culturas son respuesta de su propia historia y de su "incapacidad" para cambiar (Fetcher y Walsh, 2010) hacia un modelo de sociedad occidental, infravalorando, por ello, sus comportamientos sociales. En el caso de los españoles en Argelia, el discurso de infravaloración del otro se sustenta en el pasado histórico reciente. La tardía independencia del país respecto a Francia y la cruenta guerra civil que sufrió la sociedad argelina entre 1989 y 1999 , 
además del pasado político de carácter socialista, son los argumentos que los expatriados utilizan para justificar actitudes y prácticas que consideran "inferiores" como aparece en el estudio de Korpela sobre los Westerners en India (2010). Sobre las actitudes de los argelinos en el ámbito laboral, Alfredo afirma que: "su cultura es la de ir a trabajar, pero parar en cuanto puedan. Culpan a cualquier otro, el día a día es convencerles de que tienen que trabajar". De forma similar, Encarni expone que: "los argelinos no tienen cultura del trabajo. Si llegan tarde o pierden clase ni se plantean el hecho de ir otro día a recuperarla [...] Siguen con la idea de que ganaron la guerra [de independencia] y ese fue un hecho excepcional, pero ahora no se plantean que hay que seguir adelante formando un país. Ellos no entienden el trabajo como nosotros" (Encarni, pareja, expatriada en 2008). Para el estudio de los singapurenses y británicos expatriados en China analizados por Yeoh y Willis (2005), es la Revolución Cultural China el elemento histórico central en sus discursos para justificar la "degeneración moral" e "innata" de la cultura china (ibid: 277).

Esta jerarquización del mundo hecha por los expatriados españoles se traduce en distanciamiento de la población local y en actitudes elitistas que son censuradas, sobre todo, por la población española que "sale de la burbuja" y se relaciona con personas argelinas. En este sentido, Juana, señala que "los españoles en Orán son muy elitistas, o por lo menos en el círculo con los que yo me relacionaba. La realidad es que van despreciando un poco el entorno, vamos a decirlo así, desprecian y no es justo porque tú estás viviendo ahí y estás obteniendo unos beneficios" (Juana, pareja, primera vez en Argelia en 2006). El rechazo también se produce hacia comportamientos estereotipados asociados a la nacionalidad española, como de forma similar una parte de británicos rechaza el consumo de alcohol para no ser etiquetados como el británico estereotípico (Willis y Yeoh, 2002). Por ello, la mayoría de los estudios que trabajan este tema rechazan el nacionalismo metodológico como forma de análisis, ya que los grupos de migrantes, como en el caso de los españoles en Argelia, no se sienten un colectivo uniforme. Estos tienden a identificarse más con las características de su sector económico de trabajo y no con una identidad nacional. En este sentido, Lourdes, afirma que: "No soy muy pro españolismo, no me va tanto la diplomacia, ni beber cerveza. En Argel iba más a las fiestas que se hacían en las 
casas. Había otro ambiente más de piña" (Lourdes, 34 años, sector público, residente en Orán).

En definitiva, observamos como el sentimiento cosmopolita de estas personas emerge cuando se relacionan con otros expatriados, sin realizar un verdadero acercamiento a la sociedad argelina. En este sentido, el cosmopolitismo que profesan los expatriados españoles se aproxima a la visión crítica propuesta por Beck (2008), Beck y Grande (2006) y otros colegas que entiende el cosmopolitismo como una derivada de un contexto global en riesgo que siente miedo de la multiplicidad de culturas y de la relatividad en cuanto a las diferentes posiciones sociales que se pueden ocupar en diferentes esquemas sociales (Beck, 2008: 27). Por otro lado, la movilidad laboral hacia países emergentes sobre los que el imaginario se ha creado en base al desconocimiento o los estereotipos, en este caso sobre la cultura musulmana, provocan discursos y actitudes coloniales respecto a la sociedad local, lejos de la aceptación.

\section{CONCLUSIÓN}

La movilidad laboral entre España y Argelia se ha convertido en una estrategia para evitar el desempleo, dadas las condiciones del mercado laboral español, precarizado y desestructurado por las consecuencias de la crisis económica y social. La movilidad laboral intra-empresa ha pasado de ser una característica de movilidad moderna y/o cosmopolita, símbolo de estatus y de carácter aventurero, a ser una práctica necesaria y obligatoria desarrollada por trabajadores precarios que se alejan de la visión moderna del expatriado. En el afán por mantener el empleo, las personas expatriadas españolas en Argelia han adaptado sus estrategias transnacionales a un contexto de crisis, que les ha obligado a modificar sus itinerarios y proyectos transnacionales. Esta necesidad ha dado lugar una multiplicidad de formas de movilidad que pasan, en su mayoría por procesos de sedentarización hacia formas de movilidad más cercanas al asentamiento.

Estas personas expatriadas tampoco encajan en la representación clásica del trabajador nómada cosmopolita, curioso por adoptar y conocer otras culturas, adquiriendo un ethos cosmopolita reconocido por empresas y sujetos inmóviles. Por el contrario, estas personas 
muestran un carácter cosmopolita dentro de las burbujas o jaulas de oro de la expatriación, en las que sienten sus valores y cultura occidental compartida con otras personas, aislándose de la diferencia que representa el "otro" argelino. Marchar a un país del sur, sobre el que los expatriados mantienen un imaginario elaborado sobre los estereotipos asociados a las sociedades musulmanas y el desconocimiento de la historia y cultura del país, da lugar a discursos y prácticas coloniales que señalan como "inferior" a la sociedad de destino. Un posicionamiento que justifican sobre la diferencia cultural y la desestructuración del país debido a la guerra civil. Para algunos expatriados, el paso del tiempo y el aislamiento los lleva a romper la burbuja y a comenzar a compartir espacios públicos con la sociedad argelina mediante las prácticas diarias, mientras que otros, mantienen una experiencia transnacional aislada de la población local.

Esta tendencia migratoria hacia Argelia, propiciada por la crisis actual, se ha ampliado en los últimos años a otros actores sociales como los pequeños empresarios y personas que de forma individual se marchan a Argelia sin un contrato de trabajo. En este artículo hemos querido presentar los cambios que la crisis ha introducido en la visión idílica del expatriado móvil, imperante en la literatura científica, para demostrar que la expatriación a un destino del Sur culturalmente diferente se percibe como una acción impuesta y no como una forma de movilidad cosmopolita de la era de la globalización.

\section{REFERENCIAS BIBLIOGRÁFICAS}

Beaverstock, J. V. (2005): «Transnational elites in the city: British highlyskilled inter-company transferees in New York city's financial district». Journal of Ethnic and Migration Studies 31(2), pp. 245-268.

Beck, U. y Grande, E. (2006): La Europa Cosmopolita. Sociedad y política en la segunda modernidad. Paidós Estado y Sociedad.

BECK, U. (2008): «Mobility and the cosmopolitan perspective». Pp. 25-35. Tracing Mobilities: Towards a Cosmopolitan Perspective. Aldershot: Ashgate.

Bochove, M. y Engbersen, G. (2015): «Beyond cosmopolitanism and expat bubbles: challenging dominant representations of knowledge workers and trailing spouses». Population, Space and Place 21(4), pp. 295-309. 
Bourdieu, P. (1989): «Social space and symbolic power». Sociological theory 7(1), pp. 14-25.

Bredeloup, S. (2016): De L'Europe vers les Suds: nouvelles itinérances ou migrations à rebours?. Autrepart 77.

Cabezón Fernández, M. J. (2017): «Las migraciones en la agenda hispanoargelina. De la realidad social a la invisibilidad bilateral». Revista de estudios internacionales mediterráneos 22, pp. 77-108.

Cabezón Fernández, M. J. y Sempere Souvannavong, J. D. (2015): Las nuevas movilidades entre España y Argelia, Valencia: Tirant Humanidades.

Coles, A. y Walsh, K. (2010): «From trucial state to postcolonial city? The imaginative geographies of British expatriates in Dubai». Journal of Ethnic and Migration Studies 36:8, 1317-1333.

Cortes, G. y FARET, L. (2009): La circulation migratoire dans l'ordre des mobilités. Les circulations transnationales.

DAHINDEN, J. (2010): «The dynamics of migrants' transnational formations: Between mobility and locality». Pp. 51-72. Diaspora and Transnationalism: Concepts, Theories and Methods. Amsterdam University Press

Domingo, A. y SABATER, A. (2012): «Crisis económica y emigración: la perspectiva demográfica». Anuario de la inmigración en España 59-88.

Fabbiano, G. (2016): “Expats”,"installés” et "pionniers": mobilités contemporaines, mondes sociaux et dynamiques postcoloniales des Français en Algérie». Autrepart (1), pp. 17-33.

FAIST, T. (2013): «The mobility turn: a new paradigm for the social sciences?» Ethnic and Racial Studies 36(11), pp. 1637-1646.

Fechter, A. M. y Walsh, K. (2010): «Examining "expatriate” continuities: Postcolonial approaches to mobile professionals». Journal of Ethnic and Migration Studies 36(8), pp. 1197-1210.

Hannerz, U. (1990): «Cosmopolitans and locals in world culture». Theory, Culture \& Society, 7(2), pp. 237-251.

JENSEN, A. (2011): «Mobility, space and power: on the multiplicities of seeing mobility». Mobilities, 6(2), pp. 255-271.

MeIER, L. (2015): Migrant professionals in the city: local encounters, identities and inequalities. Routledge advances in Sociology. New York.

Mendoza, C. y Guitart, A. O. (2006): «Hacer las Américas. Migrantes españoles de alta calificación en la ciudad de México». Documents d'anàlisi geogràfica (47), pp. 93-114.

Korpela, M. (2010): "A postcolonial imagination? Westerners searching for authenticity in India». Journal of Ethnic and Migration Studies, 36:8, pp. 1299-1315.

Lafleur, J. M. y StaneK, M. (2017): «EU Migration and the Economic Crisis: Concepts and Issues». In South-North Migration of EU Citizens in Times of Crisis (pp. 1-14). Springer International Publishing.

LeOnard, P. (2010): "Work, identity and change? Post/colonial encounters in Hong Kong». Journal of Ethnic and Migration Studies 36(8), pp. 12471263. 
LevitT, P. y Schiller, N. G. (2004): «Conceptualizing simultaneity: A transnational social field perspective on society». International migration review 38(3), pp. 1002-1039.

López-SALA, A. y Oso, L. (2015): «Inmigración en tiempos de crisis: dinámicas de movilidad emergentes y nuevos impactos sociales». Migraciones. Publicación del Instituto Universitario de Estudios sobre Migraciones, (37), pp. 9-27.

Ortega, A. S. (2013): «Fuga de cerebros y crisis en España: los jóvenes en el punto de mira de los discursos empresariales». Áreas. Revista Internacional de Ciencias Sociales, (32), pp. 125-137.

Oso, L.; SÁrz López, A. y Cortés, A. (2017): «Movilidades cruzadas» en un contexto de crisis: «Una propuesta teórica para el estudio de la movilidad geográfica y social, con un enfoque de género, transnacional e intergeneracional.» Monográfico «Migraciones y movilidad social: escalando la jerarquía social en el espacio transnacional». Revista Española de Sociología, 26, 2, 293-306.

Rodríguez-Fariñas, J.; Romero-Valiente, J. M.; Hidalgo-Capitán, A. L. (2017): «Los exiliados económicos. La nueva emigración española a Argentina (2008-2015)». Iberoamerican Journal of Development Studies, forthcoming

Rodríguez-Fariñas, M. J.; Romero-Valiente, J. M. y Hidalgo-Capitán, A. L. (2016): «Los exiliados económicos. La nueva emigración española a México (2008-2014)». Scripta Nova. Revista Electrónica de Geografía y Ciencias Sociales 20.

Parella, S. y Petroff, A. (2013): «Migración de retorno en España: salidas de inmigrantes y programas de retorno en un contexto de crisis». Anuario de la Inmigración en España, pp. 61-88.

SASSEN, S. (2003): "Reading the city in a global digital age». Cities in Globalization, 231.

Schiller, N. G.; Basch, L. y Blanc-Szanton, C. (1992): «Towards a definition of transnationalism». Annals of the New York academy of sciences 645(1).

Sempere Souvannavong, J. D.; Cabezón Fernández, M. J. (2016): «La mobilité des travailleurs espagnols dans l'ouest de l'Algérie», Autrepart 2016/1, N 77, pp. 35-50.

Sheller, M. \& Urry, J. (2006): «The new mobilities paradigm». Environment and planning A, 38(2), pp. 207-226.

SKLAIR, L. (1997): «Social movements for global capitalism: the transnational capitalist class in action». Review of International Political Economy 4(3), pp. 514-538.

VAILATI, A. y RiaL, C. (2016): Migration of Rich Immigrants: Gender, Ethnicity and Class. Springer.

Vertovec, S. y Cohen, R. (2002): Conceiving cosmopolitanism: theory, context and practice. Oxford, Oxford University Press, pp. 1-22

Villanueva, E. T. (2009): «Las grandes empresas constructoras españolas. Crecimiento e internacionalización en la segunda mitad del siglo XX». Información comercial española, (849), p. 113. 
Weiß, A. (2005): «The transnationalization of social inequality: Conceptualizing social positions on a world scale». Current Sociology 53(4), 707-728.

Willis, K. y YЕOH, B. (2002): «Gendering transnational communities: a comparison of Singaporean and British migrants in China». Geoforum 33(4), pp. 553-565.

Yеон, B. S. y Willis, K. (2005): «Singaporean and British transmigrants in China and the cultural politics of contact zones». Journal of Ethnic and Migration Studies 31(2), pp. 269-285.

Zoubir, Y. y Amirah, H. (2008): El Magreb. Realidades nacionales y dinámicas regionales. Síntesis, Madrid. 